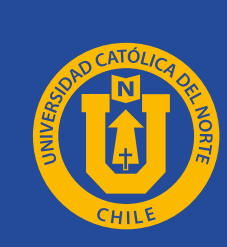

Estudios

Atacameños

ARQUEOLOGÍA

Y ANTROPOLOGÍA

SURANDINAS

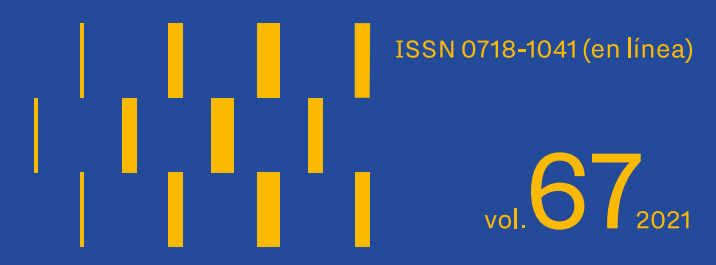

\title{
In Memoriam George Serracino Calamatta (1941-2021)
}

Sus años en Europa

George Serracino Calamatta nació en Malta un 8 de diciembre de 1941, en la localidad de isla de Gozo, Victoria (Capital). Su educación primaria la realizó en la ciudad medieval de Valletta (Malta), entre los años 1946 y 1950, para luego pasar al Colegio Arzobispal en Floriana (Malta) entre 1950 y 1959. Sus estudios superiores universitarios los realizó en el Loyola House of Studies en Naxxar en Malta (1959-1963), para después cursar Filosofía en la Universidad Gregoriana de Roma entre los años 1963 y 1966, titulándose con la máxima distinción.

Su pasión por la arqueología se empieza a gestar el mismo año 1966, cuando obtiene un "Diploma en Arqueología", tras cursar estudios en el Instituto de Arqueología Cristiana en Roma. Entre 1966 y 1968, mientras dedica sus lecturas a la arqueología europea, ejerce como profesor de Historia Antigua y de Arte en St. Aloysius College y en el Loyola House of Studies en Malta. Asimismo, en esos años fue miembro de la Sociedad de Arqueología de Malta. Entre 1967 y 1968 fue el encargado de dirigir diversas exposiciones sobre las catacumbas de Malta, la arqueología de Malta, arqueología medieval de Malta y la cultura maltesa.

\section{Su incorporación a la Universidad de Chile}

Llegó a Chile el año 1968. Ya en el año 1970 se incorpora al grupo de trabajos en Arqueología que dirige el arqueólogo -y luego premio nacional de Historia- Mario Orellana Rodríguez, quien recién asumía la dirección del fundado Departamento de Antropología y Arqueología de la Universidad de Chile. En esta etapa el señor Serracino participa en los trabajos de excavación del Alero de Toconce (1970), Confluencia 1 (cerca de Chiu-Chiu, 1970-1973), Loa Oeste 3 (1972) y Guatín, cerca de San Pedro de Atacama (1972-1973). Además, fue profesor de Prehistoria, con doce horas a contrata, en el Departamento de Ciencias Antropológicas y Arqueología de la Universidad de Chile, entre los años 1971 (enero) y 1973 (febrero).

\section{Sus trabajos en la Universidad del Norte}

En julio de 1973 se incorporará a la Universidad del Norte en Antofagasta, que lo contrata como investigador en el Museo Arqueológico de San Pedro de Atacama, integrando el grupo de trabajo que llevaba adelante desde la década de 1950 el R. P. Gustavo Le Paige, s.j. Viajó a Estados Unidos para realizar estudios de posgrado en la Universidad de Cornell (Ithaca, NY) entre 1974 y 1976, obteniendo el grado de Magíster en Antropología. Regresa en 1977, y se reincorpora a la Universidad del Norte, donde mantiene su cargo de investigador en el citado 
museo. En agosto de 1981 es contratado como académico -con media jornada- en el Departamento de Historia y Arqueología, luego de que fuera cesado en sus labores de investigador en el museo con fecha 23 de febrero de 1981. Dejará definitivamente la Universidad del Norte el 30 de julio de 1982.

\section{Sus publicaciones y sus trabajos como investigador}

George Serracino fue un connotado investigador en la arqueología, y su aporte a la ciencia arqueológica en Chile se verá reflejado en diversos trabajos que pasamos a señalar. Entre los años 1971 y 1973 aparecerán en el Boletín de Prehistoria de Chile (números 3 y 4), en las Actas del VI Congreso de Arqueología Chilena y en Antropología Nueva Época (número 1) sus primeros trabajos realizados en Confluencia 1 (informe preliminar), el uso de la computación en el análisis del material lítico del Río Salado, y un "Informe Etnobotánico de Guatín”, y finalmente las estructuras de Ghatchi en Norte Grande, volumen 2.

Ya asentado en la Universidad del Norte (específicamente en San Pedro de Atacama), le corresponderá ser el editor de los primeros números de la prestigiosa revista Estudios Atacameños, actualmente vigente. Se pueden leer en los números 1 al 6 diversos trabajos e informes de autoría de Serracino, años 1973 a 1978.

Le correspondió a él escribir el primer editorial del número 1 de la revista Estudios Atacameños, del que queremos destacar el siguiente párrafo:

La arqueología tuvo el desarrollo más grande entre todos los estudios de la zona y sigue siendo la materia sobre la cual más se escribe. Sin embargo, esta revista tiene el objeto de abarcar otras materias referentes a ella, aun cuando este número esté dedicado casi exclusivamente a la arqueología. Esto ocurre porque desde 1968 los Anales de la Universidad del Norte, que han sido los portavoces de la investigación en esta zona, tomaron otro rumbo mientras que las investigaciones seguían su curso sin contar con un medio para comunicar sus resultados. Por lo tanto, un sinnúmero de artículos de investigadores extranjeros y nacionales quedó archivado en el museo, lo que a su vez nos garantiza una larga vida para la revista por cuanto hay mucho material para publicar. Un punto que queremos destacar es que esta revista tiene sus puertas abiertas para todo tipo de crítica científica sobre el problema atacameño y especialmente sobre los artículos que se publiquen en ella.

He aquí la base, el cimiento sólido del inicio de la investigación arqueológica y luego de otras áreas de la historia y ciencias sociales en el norte de Chile, que marcarán esta destacada revista de la Universidad del Norte (hoy Universidad Católica del Norte) con un prestigio nacional e internacional del más alto nivel.

Son diversos los trabajos publicados por Serracino en dicha revista, destacándose "Informes de trabajo del proyecto Guatín", "Proyecto Tulán", "Movimiento de cazadores y recolectores en la Cordillera de Los Andes", "Vida Pastoril en la Precordillera Andina”, "Cerámica de Guatín", “4 pozos de sondeo en Tulor 4", "Tumbre: sitios estacionales en la industria tambilliense”. 
Mención especial merece su paso por el pueblo de Caspana donde, además de dedicarse a su ejercicio sacerdotal, no abandonó el trabajo arqueológico liderando el Museo Arqueológico.

En el nuevo siglo fue académico en la Universidad Metropolitana de Ciencias de la Educación, en Santiago. Allí hizo clases de Antropología y también dedicó tiempo a la investigación en el sistema educacional, en el Departamento de Formación Pedagógica.

Hay que destacar, finalmente, que George Serracino entró a la Compañía de Jesús el 1 de octubre de 1959. Estudió teología en la Pontificia Universidad Católica de Chile, entre los años 1970 y 1974, dejando la Compañía de Jesús en 1978. Lo anterior no impidió que se ordenara, ejerciendo el sacerdocio en San Pedro de Atacama y especialmente en el pueblo de Caspana. Luego dejará definitivamente los hábitos para casarse con doña Ana Isabel Matus de la Parra Becerra. Tiene un hijo, Jonathan George, y tres nietos.

Su muerte nos entristece, pero a la vez nos permite escribir estas breves palabras de su vida, destacando especialmente su labor investigadora en la arqueología chilena.

Fernando Orellana Torres ${ }^{1}$ (D) https://orcid.org/0000-0001-5409-7758

Mario Orellana Rodríguez ${ }^{2}$ (D) https://orcid.org/0000-0002-3562-7431

${ }^{1}$ Universidad Católica del Norte, CHILE. Email: forellana@ucn.cl

${ }^{2}$ Sociedad Chilena de Historia y Geografía, CHILE. Email: morellanar30@hotmail.com 